\title{
1-Methylcyclopropene Has a Variable Effect on Adventitious Root Emergence from Cuttings of Two Sweetpotato Cultivars
}

\author{
Arthur Villordon ${ }^{1}$ \\ LSU AgCenter Sweet Potato Research Station, 130 Sweet Potato Road, \\ Chase, LA 71324
}

Christopher Clark

LSU AgCenter Department of Plant Pathology and Crop Physiology, 302 Life Sciences Building, Baton Rouge, LA 70803-2120

\author{
Don LaBonte \\ LSU AgCenter School of Plant, Environmental, and Soil Sciences, 137 J.C. \\ Miller Hall, Baton Rouge, LA 70803-2120
}

Nurit Firon

Institute of Plant Sciences, The Volcani Center, Agricultural Research Organization, P.O. Box 6, Bet Dagan, 50250, Israel

Additional index words. Ipomoea batatas, ethylene, epidermal cell death

\begin{abstract}
This study aimed to investigate the effect of 1-methylcyclopropene (1-MCP) on adventitious rooting in two sweetpotato cultivars. Experiments with 'Beauregard' and 'Evangeline' sweetpotato cuttings revealed differential adventitious root (AR) emergence responses to 1-MCP application. 'Beauregard' AR count and length decreased with 1-MCP application in two of four experiments. In contrast, 1-MCP did not influence 'Evangeline' root count. However, 'Evangeline' root length decreased in three of four experiments. Trypan blue staining of 'Beauregard' nodal tissue with delayed AR primordia emergence showed localized dead tissue in the general area where ARs emerge. The degree of staining appeared to correspond with the stage of $A R$ emergence with the staining becoming more intense around the time an AR primordium eventually emerged through a crack in the epidermis. This response agrees with reported results of ethylene-mediated AR emergence in other plant species. These results also appear to suggest that 'Beauregard' and 'Evangeline' cuttings differ in ethylene sensitivity. This represents the first evidence of genotype-specific ethylene involvement in adventitious rooting of sweetpotato cuttings.
\end{abstract}

The emergence of ARs in sweetpotato cuttings represents an important phase in plant establishment and represents the initial phase of storage root formation (Togari, 1950). The

\footnotetext{
Received for publication 10 Aug. 2012. Accepted for publication 9 Oct. 2012.

Portions of this research were supported by Research Grant No. US-4015-07 from BARD, the U.S.-Israel Binational Agricultural Research and Development, USDA NIFA SCRI 2009-51181-06071, and the Louisiana Sweetpotato Advertising and Development Fund.

We thank AgroFresh Inc. for providing financial support and for supplying 1-methylcyclopropene (SmartFresh) used in this study.

Approved for publication by the Director of the Louisiana Agricultural Experiment Station as manuscript number 2012-260-6912.

Mention of trademark, proprietary product or method, and vendor does not imply endorsement by the Louisiana State University Agricultural Center nor its approval to the exclusion of other suitable products or vendors.

${ }^{1}$ To whom reprint requests should be addressed; e-mail avillordon@agcenter.lsu.edu.
}

knowledge of the influence of external and internal variables on adventitious rooting is important in identifying practical methods to optimize plant stand and production efficiency. The role of plant hormones in adventitious rooting has been a source of confusion not only in sweetpotatoes but in other plant species as well. In fact, Kays (1985) mentioned that although gibberellic acid, auxin, ethylene, cytokinin, and abscisic acid have been detected in sweetpotatoes, their specific roles have not been elucidated. Recently, Mortley et al. (2008) reported that 12 stem cuttings of the Whatley/ Loretan cultivar produced $\approx 7 \mathrm{~nL} \cdot \mathrm{L}^{-1}$ of ethylene after $5 \mathrm{~d}$. In other plant species, ethylene has been documented to promote, inhibit, or have no influence on adventitious rooting (Harbage and Stimart, 1996; Mudge and Swanson, 1978; Rapaka et al., 2008). The knowledge of the influence of ethylene in adventitious rooting is useful to identify commercially available technologies that can be used to improve quality and uniform establishment of cuttings. For example, Serek et al. (1998) used the ethylene inhibitors 1-MCP and silver thiosulfate to retard storage-induced leaf yellowing in cuttings from Dendranthema grandiflorum, Pelargonium zonale, and Hibiscus rosa-sinensis. However, they observed reduced adventitious rooting in both fresh and stored cuttings. A follow-up study by Rapaka et al. (2008) determined that endogenous carbohydrate interacted with the action of ethylene to regulate leaf senescence and AR formation in Pelargonium cuttings. Mergemann and Sauter (2000) presented evidence that ethylene induced epidermal cell death at the site of $\mathrm{AR}$ emergence in rice (Oryza sativa), allowing preformed AR initials to emerge through the crack in the epidermis. The role of ethylene-induced cell death in AR emergence in sweetpotatoes has not been investigated. Experiments were conducted to assess the effect of 1-MCP in adventitious rooting in cuttings of two sweetpotato cultivars grown in Louisiana. A secondary objective was to investigate the possible role of epidermal cell death at the site of sweetpotato AR emergence, similar to the results described by Mergemann and Sauter (2000) in rice. Our hypothesis is that endogenous ethylene is involved in epidermal cell death at the site of AR emergence that results in appearance of ARs in sweetpotato cuttings.

\section{Materials and Methods}

Plant material. The greenhouse experiments were conducted in Chase, LA (lat. $32^{\circ} 6^{\prime} \mathrm{N}$, long. $\left.91^{\circ} 42^{\prime} \mathrm{W}\right)$. On 1 Oct. 2011, virus-tested 'Beauregard' and 'Evangeline' Generation 1 (G1) storage roots were bedded in washed river sand and served as a source of transplants for all experiments. In each experiment, cuttings with five to seven fully opened leaves and no visible emerged root primordia were obtained from each cultivar between 1400 to $1600 \mathrm{HR}$. It was observed that over the duration of the experiments (Nov. 2011 to Feb. 2012), the presence of nodes with emerged root primordia could not be avoided. Subsequently, later experiments (Jan. and Feb. 2012) included cuttings with nodes that showed visible root primordia. Cuttings were placed in plastic containers (volume $=99 \mathrm{~L}$ ) within 10 min after harvesting for 1-MCP treatments.

1-Methylcyclopropene treatment and growing conditions. 1-MCP solution was prepared by adding SmartFresh ${ }^{\mathrm{TM}}$ research tablets (AgroFresh Inc., Springhouse, PA) to a plastic release vial containing an activator tablet and $18 \mathrm{~mL}$ activator solution. Treatment levels were 1 and $2 \mu \mathrm{L} \cdot \mathrm{L}^{-1}$. The release vial was placed adjacent to a battery-powered fan $(5 \mathrm{~cm}$ in diameter). The plastic container was sealed within $30 \mathrm{~s}$ with plastic tape and stored in dark conditions. Temperatures ranged from 24 to $27^{\circ} \mathrm{C}$ during the treatments. Untreated cuttings were also placed in sealed plastic containers. After the $24 \mathrm{~h}$ of 1-MCP treatments, cuttings were set by burying two to three nodes under the growth medium (washed river sand) contained in $10 \mathrm{~cm}$-diameter polyvinyl chloride pots (height $=30 \mathrm{~cm}$ ) with detachable plastic bottoms. Cuttings were watered with $200 \mathrm{~mL}$ distilled water. At the conclusion of each 
rooting experiment $(4 \mathrm{~d})$, growth substrate moisture content was $\approx 50 \%$ of field capacity $[\approx 7 \%$ volumetric water content as measured with $\mathrm{ECH}_{2} \mathrm{O}$ soil moisture sensors (Model EC-5; Decagon Devices Inc., Pullman, WA)] inserted vertically at the $2-$ to $7-\mathrm{cm}$ depth. Fertilizer application consisted of $0.76 \mathrm{~g}$ of $5 \mathrm{~N}-$ $20 \mathrm{P}-20 \mathrm{~K}$ per pot. The greenhouse temperature regime was $29^{\circ} \mathrm{C}$ for $14 \mathrm{~h}$ (day) and $18^{\circ} \mathrm{C}$ for $10 \mathrm{~h}$ (night), and relative humidity (RH) averaged $60 \%$. Temperature and $\mathrm{RH}$ were monitored at the canopy level using an integrated temperature and RH sensor (Model RHT; Decagon Devices Inc.). Photosynthetic photon flux $(P P F)$ for all experiments ranged from 150 to $1133 \mu \mathrm{mol} \cdot \mathrm{m}^{-2} \cdot \mathrm{s}^{-1}$. Supplementary lighting was provided using white fluorescent lights $\left(\approx 42 \mu \mathrm{mol} \cdot \mathrm{m}^{-2} \cdot \mathrm{s}^{-1} P P F\right)$ for $14 \mathrm{~h}$ per day. $P P F$ was measured at the canopy level with a quantum sensor (Model QSO-S; Decagon Devices Inc.).

Data collection and experimental design. In all experiments, plants were grown for $4 \mathrm{~d}$ after which near-intact root systems were collected. In previous work, we have determined that 'Beauregard' formed ARs that underwent rapid initial growth after $5 \mathrm{~d}$ (Villordon et al., 2009). Harvesting at an earlier date permitted characterization of initial AR root emergence. At harvest, the detachable plastic bottoms were removed and the pot was tilted and the growth substrate was gradually removed using a stream of water. The planting dates were 10 Nov. 2011, 17 Nov. 2011, 26 Jan. 2012, and 10 Feb. 2012. There were five replicates (one plant per pot $=$ one replicate) in each experiment. All experiments were arranged as randomized complete blocks repeated across planting dates. As a result of the variability of the number of ARs per plant, there were unequal subsample sizes. In all experiments, intact ARs were floated on waterproof trays and scanned using a specialized Dual Scan optical scanner (Regent Instruments Inc., Quebec, Canada). The acquisition and image analysis software was WinRHIZO Pro (Version 2009c; Regent Instruments Inc.). Debris removal among scanned images was performed manually using the WinRhizo Pro Edition working mode. Debris consisted mainly of images of sand particles. The length of the AR main axis was measured using ImageTool (Univ. of Texas Health Science Center at San Antonio, available from $<\mathrm{ftp} / / /$ maxrad6.uthscsa.edu $>$ ). Entire node sections with non-emerged roots were excised and subjected to trypan blue staining (Desmond et al., 2008) to determine the presence of cell death at the site of adventitious root emergence (Mergemann and Sauter, 2000). Entire node sections were immersed in $0.4 \%$ trypan blue (Sigma Chemical Co., St. Louis, MO) for $3 \mathrm{~min}$ and washed with water. Microscopic analysis of staining patterns was performed immediately using a stereo microscope. To verify ethylene production by 'Beauregard' and 'Evangeline' cuttings during the application of experimental treatments, a CI-900FK portable ethylene gas analyzer equipped with a field kit (CID Bio-Science Inc., Camas, WA) was used. Modifications were made on containers (volume $=99 \mathrm{~L}$ ) by installing sampling ports on the covers to allow access of the CI-900FK sampling wand. In all experiments, five cuttings of each cultivar were weighed and immediately placed in containers within $5 \mathrm{~min}$ of harvesting for the imposition of experimental treatments. Sampling was performed every $6 \mathrm{~h}$ by attaching the CI-900FK sampling wand to the sampling ports and recording the ethylene concentration after the instantaneous readings stabilized $(\approx 10 \mathrm{~min})$. Calibration was verified using an ethylene analytical standard (Sigma-Aldrich Inc., St. Louis, MO). There were three replicates per cultivar $X$ treatment combination.

Statistical analysis. As a result of the variability of the state of AR primordia emergence across varieties and time, rooting experiments were analyzed separately by variety and experiment. Root length and count data were transformed using $\log 10$ and square root transformation, respectively, to normalize the residuals. The unbalanced data sets were analyzed using SAS Proc Mixed (SAS Version 9.1; SAS Inc., Cary, NC).

\section{Results and Discussion}

'Beauregard' and 'Evangeline' cuttings treated with 1-MCP showed variable AR emergence and length across four experiments that were conducted over time (Table 1). In 'Beauregard', cuttings had delayed AR emergence in the first two experiments, as exemplified by the results from the second experiment shown in Figure 1. In 'Evangeline', AR count did not vary among 1-MCP treatments across all experiments, which was similar to the results from the second experiment shown in Figure 1. However, 'Evangeline' AR length was significantly shorter in three of four experiments at the $2 \mu \mathrm{L} \cdot \mathrm{L}^{-1}$ level. In general, these results are similar to those reported by Serek et al. (1998) where ethylene inhibitors reduced AR count and length in Dendranthema, Pelargonium, and Hibiscus cuttings. Trypan blue staining of 'Beauregard' nodal sections with delayed AR emergence showed variable staining responses ranging from no visible stained epidermal tissue (Fig. 2A), patchy staining (Fig. 2B), contiguous tissue-specific staining (Fig. 2C), and staining of cracked epidermal tissue at the periphery of a protruding AR primordium (Fig. 2D). Figure 2 depicts the progressive death of epidermal tissue at the site of AR primordium emergence and is very similar to that observed by Mergemann and Sauter (2000) in ethephontreated rice nodal epidermis. They proposed that ethylene-mediated adventitious rooting is an adaptive mechanism in deepwater rice where the emergence of AR primordia is dependent on an appropriate signal, i.e., submergence, which in turn is mediated by ethylene. Mortley et al. (2008) first reported ethylene emission by sweetpotato cuttings in a closed system after a period of $5 \mathrm{~d}$. Although our ethylene measurements were taken over a 24-h period, the data generally indicate a trend toward a lower concentration in the control treatment at the end of the sampling period, in part confirming the observations by Mortley et al. (2008) (Fig. 3). During the application of $1-\mathrm{MCP}$ in sealed containers, 'Evangeline' and 'Beauregard' cuttings showed differential ethylene accumulation depending on 1-MCP treatment level. Ethylene concentration in 'Beauregard' control and $1 \mu \mathrm{L} \cdot \mathrm{L}^{-1}$ treatments showed an initial increase during the first $6 \mathrm{~h}$ but declined thereafter with the control treatment showing relatively higher ethylene concentration at the end of the treatment period. In 'Beauregard' cuttings exposed to the $2 \mu \mathrm{L} \cdot \mathrm{L}^{-1}$ treatment, ethylene concentration was initially similar compared with the other treatment levels but showed a relatively higher accumulation rate over the next $18 \mathrm{~h}$ followed by a decline in the last $6 \mathrm{~h}$ of the treatment period. Ethylene concentrations in 'Evangeline' were initially similar during the first $12 \mathrm{~h}$ regardless of treatment levels. Starting at $18 \mathrm{~h}$, ethylene accumulation varied with the control and $2 \mu \mathrm{L} \cdot \mathrm{L}^{-1}$ levels showing a relatively higher accumulation rate compared with the $1 \mu \mathrm{L} \cdot \mathrm{L}^{-1}$

Table 1. Adventitious root count and length at $4 \mathrm{~d}$ after transplanting among 'Beauregard' and 'Evangeline' sweetpotato cuttings subjected to 1-MCP pretreatments. ${ }^{\text {' }}$

\begin{tabular}{|c|c|c|c|c|c|}
\hline \multirow[b]{2}{*}{$\mathrm{PD}^{\mathrm{y}}$} & \multirow[b]{2}{*}{$1-\mathrm{MCP}^{\mathrm{x}}$} & \multicolumn{2}{|c|}{ Count } & \multicolumn{2}{|c|}{ Length $(\mathrm{cm})$} \\
\hline & & $\mathrm{BX}$ & EV & $\mathrm{BX}$ & EV \\
\hline \multirow[t]{3}{*}{$\overline{1}$} & 0 & $4.0 \pm 3.3 \mathrm{a}$ & $4.4 \pm 3.6 \mathrm{a}$ & $1.7 \pm 0.9 \mathrm{a}$ & $1.0 \pm 0.8 \mathrm{a}$ \\
\hline & 1 & $0 \pm 0 \mathrm{~b}$ & $4.8 \pm 3.7 \mathrm{a}$ & $0 \pm 0 \mathrm{~b}$ & $0.9 \pm 0.8 \mathrm{ab}$ \\
\hline & 2 & $0 \pm 0 \mathrm{~b}$ & $2.6 \pm 2.6 \mathrm{a}$ & $0 \pm 0 \mathrm{~b}$ & $0.7 \pm 0.5 b$ \\
\hline \multirow[t]{3}{*}{2} & 0 & $3.0 \pm 3 \mathrm{a}$ & $6.2 \pm 3.9 \mathrm{a}$ & $1.6 \pm 0.9 \mathrm{a}$ & $1.8 \pm 1.1 \mathrm{a}$ \\
\hline & 1 & $0 \pm 0 \mathrm{~b}$ & $8.6 \pm 14 \mathrm{a}$ & $0 \pm 0 \mathrm{~b}$ & $1.5 \pm 1.2 \mathrm{a}$ \\
\hline & 2 & $0.4 \pm 0.8 \mathrm{a}$ & $9.4 \pm 8.9 \mathrm{a}$ & $0.5 \pm 0.7 \mathrm{a}$ & $1.4 \pm 0.8 \mathrm{a}$ \\
\hline \multirow[t]{3}{*}{3} & 0 & $0.6 \pm 1.3 \mathrm{a}$ & $6.6 \pm 5 \mathrm{a}$ & $0.7 \pm 1 \mathrm{a}$ & $1.1 \pm 0.7 \mathrm{a}$ \\
\hline & 1 & $1.8 \pm 1.3 \mathrm{a}$ & $5.4 \pm 3.4 \mathrm{a}$ & $0.9 \pm 0.5 \mathrm{a}$ & $1.2 \pm 0.6 \mathrm{a}$ \\
\hline & 2 & $2.0 \pm 1 \mathrm{a}$ & $5.2 \pm 1.6 \mathrm{a}$ & $1.2 \pm 0.6 \mathrm{a}$ & $0.7 \pm 0.3 b$ \\
\hline \multirow[t]{3}{*}{4} & 0 & $1.6 \pm 2.3 \mathrm{a}$ & $6.2 \pm 4.3 \mathrm{a}$ & $1.5 \pm 1.8 \mathrm{a}$ & $1.7 \pm 0.9 \mathrm{a}$ \\
\hline & 1 & $3.2 \pm 2.8 \mathrm{a}$ & $1.6 \pm 1.5 \mathrm{a}$ & $2.3 \pm 1.2 \mathrm{a}$ & $0.8 \pm 0.6 \mathrm{~b}$ \\
\hline & 2 & $2.4 \pm 0.5 \mathrm{a}$ & $5.8 \pm 3.9 \mathrm{a}$ & $1.7 \pm 0.9 \mathrm{a}$ & $1.3 \pm 0.8 \mathrm{ab}$ \\
\hline
\end{tabular}

${ }^{\mathrm{z}}$ Values represent means ( \pm SEM). Means within columns within planting dates followed by a common letter are not significantly different based on Fisher's least significant difference mean separation test $(P \leq 0.05)$. Counts were square root transformed, whereas lengths were $\log _{10}$ transformed. Corresponding nontransformed values are shown. Scoring of adventitious root emergence was performed four days after planting. $\mathrm{BX}=$ Beauregard; $\mathrm{EV}=$ Evangeline.

${ }^{y} P D=$ planting date. PD 1 = 10 Nov. 2011; PD 2 = 17 Nov. 2011; PD $3=26$ Jan. 2012; PD 4 = 10 Feb. 2012. ${ }^{\mathrm{x}} 1$-MCP $=1$-methylcyclopropene treatment levels; $0=$ control; $1=1 \mu \mathrm{L} \cdot \mathrm{L}^{-1} ; 2=2 \mu \mathrm{L} \cdot \mathrm{L}^{-1}$. 
Beauregard

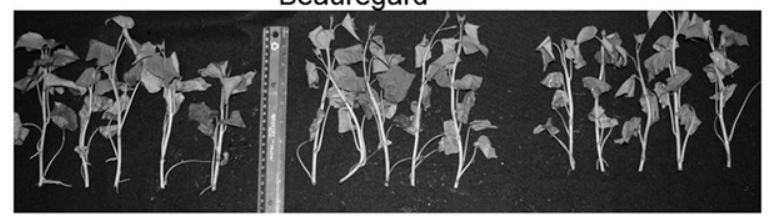

Evangeline

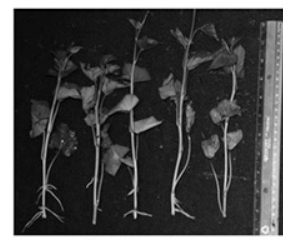

Control

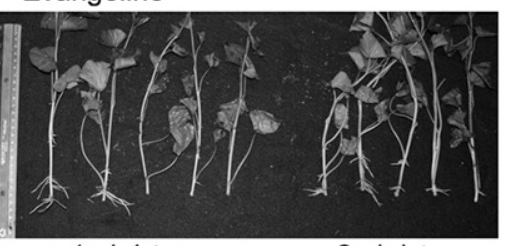

$1 \mu \mathrm{L} \cdot \mathrm{L}^{-1}$
$2 \mu \mathrm{L} \cdot \mathrm{L}^{-1}$

Fig. 1. Differential adventitious rooting of 'Beauregard' and 'Evangeline' cuttings in response to 1methylcyclopropene (1-MCP) treatment levels after $4 \mathrm{~d}$ of growth. Cuttings were treated in sealed containers for $24 \mathrm{~h}$ before planting. This experiment was planted on 17 Nov. 2011 and harvested on 21 Nov. 2011.
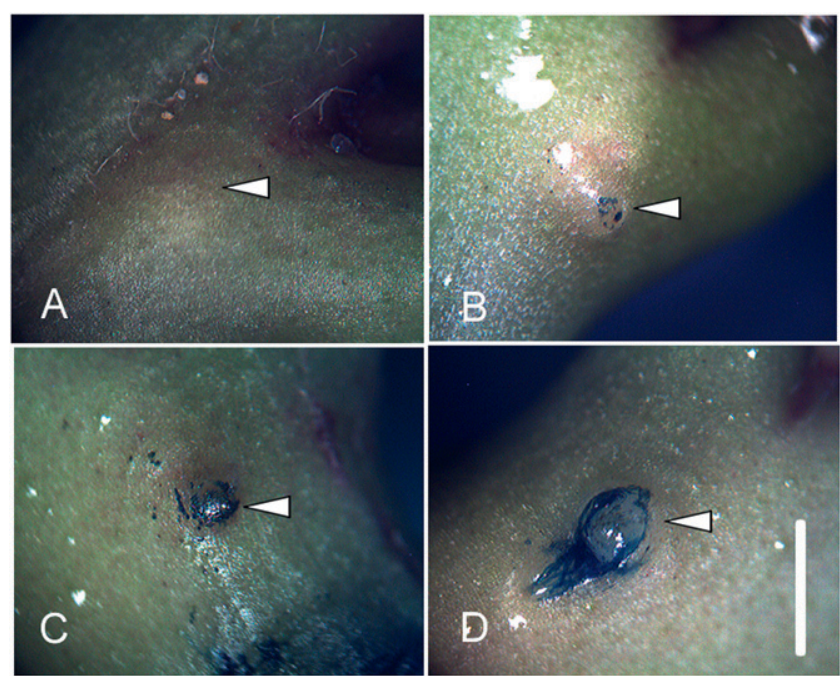

Fig. 2. Progressive emergence of adventitious roots depicted by trypan blue staining of epidermal tissue covering the primordia in buried 'Beauregard' nodes with non-emerged adventitious roots. (A) No detectable staining of epidermis; (B) patchy staining of epidermis; (C) near-contiguous tissue-specific staining of epidermis; (D) stained tissue includes cracked epidermis with emerging root initial. Descriptions of staining patterns are based on the work by Mergemann and Sauter (2000). Scale $=1.5 \mathrm{~mm}$.

treatment. The initial increase of ethylene production by 'Beauregard' and 'Evangeline' cuttings (control treatment) between 6 and $18 \mathrm{~h}$ is similar to the pattern of wound ethylene accumulation in newly harvested pelargonium cuttings that were stored in sealed containers and monitored continuously with a photoacoustic trace gas detector (Kadner et al., 2000). They reported that wound ethylene production reached a maximum after 4 to $12 \mathrm{~h}$ and was completed in $24 \mathrm{~h}$. Genotypic and temporal variability in plant tissue responses to $1-\mathrm{MCP}$ treatments have been documented previously, for example in potted foliage plant genotypes (Macnish et al., 2011) and Arabidopsis accessions (Millenaar et al., 2005). Mao et al. (2007) reported that the presence of 1-MCP reduced wound ethylene in fresh-cut 'Fuji' apples (Malus sylvestris). In contrast, it has also been documented that the presence of 1-MCP increased ethylene production in pelargonium (Pelargonium $\times$ hortorum) cuttings (Rapaka et al., 2008). In wounded mature leaf blades of citrus (Citrus sinensis), ethylene evolution was similar regardless of the presence or absence of 1-MCP (Pozo et al., 2004) during the first $48 \mathrm{~h}$ but was subsequently higher in 1-MCP-treated wounded leaves. To our knowledge, very little work has been done to investigate the role of exogenous and endogenous ethylene in sweetpotato cuttings and how ethylene interacts with other hormones, carbohydrate status, and external variables like temperature. Kadner et al. (2000) documented that storage temperature influenced ethylene emission by pelargonium cuttings. Rapaka et al. (2008) also reported that ethylene interacts with the carbohydrate status of pelargonium cuttings to help determine adventitious rooting capacity. In their experiments, Rapaka et al. (2008) harvested cuttings at 0800 and $1600 \mathrm{HR}$ to represent lowest or highest carbohydrate export capacity of source leaves, respectively. Kays et al. (1987) have previously documented that the export pool of photosynthates in sweetpotato leaves is greater during the early forenoon and late afternoon periods. In our experiments, all cuttings were harvested between 1400 and $1600 \mathrm{HR}$ to minimize possible variation in temperature and carbohydrate status effects. In commercial operations, cuttings are harvested regardless of the time of day (Thornhill, personal communication). Our results help to underscore the need to gain an understanding of the significance of ethylene activity in sweetpotato propagation. Preliminary replicated field studies appear to show that 1-MCP-treated cuttings had similar storage root yields relative to untreated cuttings (data not shown). Followup studies might focus on the possible interactive effects of 1-MCP treatment with carbohydrate status, storage temperature and duration, and transplanting conditions to identify conditions that might lead to increased survivability of cuttings. For example, Hammet (1983) presented evidence that 'Jasper' cuttings held for $3 \mathrm{~d}$ before planting had 15\% more total marketable yield relative to cuttings that were obtained and planted on the same day. A possible explanation for these results is that cuttings were planted around the time the ARs were emerging, thereby reducing the exposure of cuttings to the drying effects of sun and wind. On the other hand, high temperatures (35 to $40{ }^{\circ} \mathrm{C}$ ) have been shown to inhibit ethylene production (Yu et al., 1980) and this could conceivably influence plant establishment. It has also been shown that under drought conditions, ethylene endogenously regulates plant homeostasis and results in reduced root and shoot growth (Glick et al., 2007).

Based on the findings by Mergemann and Sauter (2000), it could be interpreted that the physical cutting of a sweetpotato stem section from the source plant is a necessary step in the signaling process for the emergence of preformed AR initials. In rice, a follow-up study appears to suggest that ethylene interacts with abscisic acid and gibberellin in initiating programmed cell death of epidermal cells that cover AR primordia (Steffens and Sauter, 2005). This work can also be used as a methodological model for conducting follow-up studies to determine if a similar mechanism exists for sweetpotato. Auxin is also implicated in AR emergence signaling ( $\mathrm{Li}$ et al., 2009). An enhanced knowledge of the role of these hormones in adventitious rooting could lead to the development of practical methods that optimize plant establishment, reduce stand loss, and increase efficiency in sweetpotato production. The differential response between 'Beauregard' and 'Evangeline' cuttings to the 1-MCP treatments provides evidence for a presumptive genotypic component not only in ethylenemediated AR emergence signaling, but possibly in other tissue-specific ethylene-mediated responses as well. 1-MCP selectively binds ethylene receptors such that ethylene cannot bind and elicit action (Blankenship and Dole, 2003). If an ethylene receptor undergoes mutation, similar to the Arabidopsis etrl-1 ethylene receptor mutation, then ethylene perception is blocked (Gamble et al., 2002). An ethylene receptor mutation can also prevent $1-\mathrm{MCP}$ from blocking the effects of ethylene. A similar mechanism might help to explain the apparent lack of differences in AR emergence 


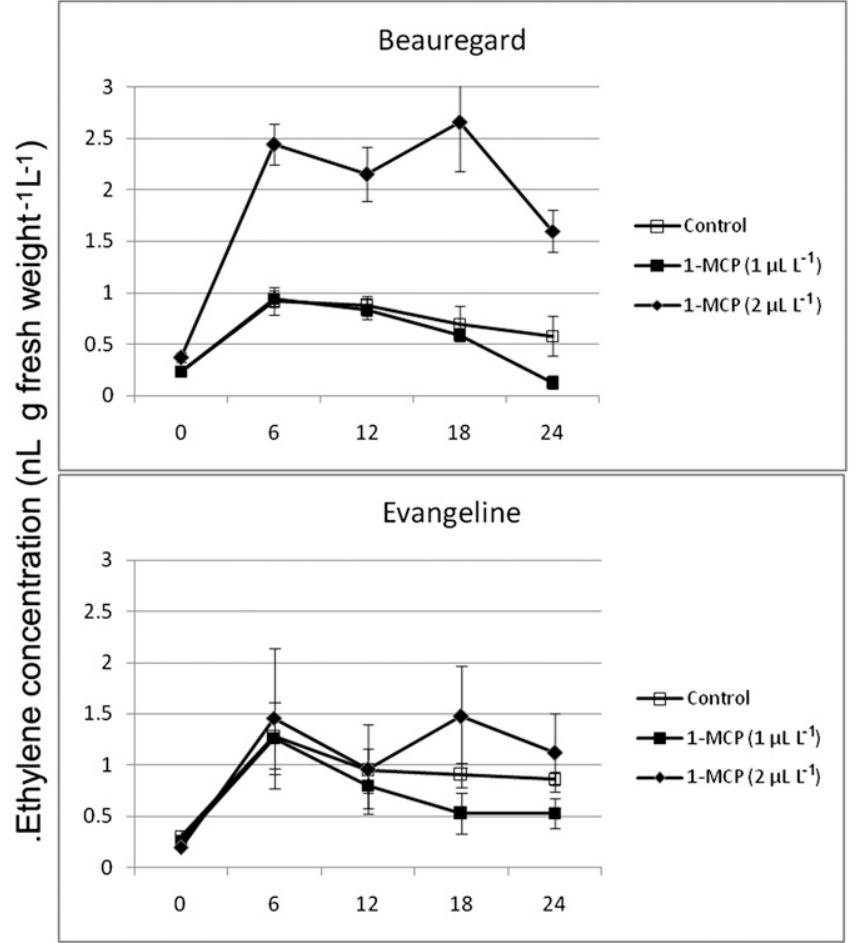

Treatment duration $(\mathrm{h})$

Fig. 3. Ethylene accumulation by 'Beauregard' and 'Evangeline' cuttings subjected to different 1methylcyclopropene (1-MCP) treatment levels in sealed containers. Data shown are means $\pm \mathrm{SE}$ of three replicates.

in 'Evangeline' cuttings treated with 1-MCP. Further studies are needed to characterize the non-response and presumptive differential perception of ethylene in 'Evangeline'. Clearly, the knowledge of the basis and effects of differential ethylene sensitivity among sweetpotato varieties can lead to the development of genotype-specific practices not only for optimizing propagation, but postharvest practices as well. In sweetpotatoes, ethylene has been implicated in wound healing (St. Amand and Randle, 1989) and loss of quality during storage (Kitinoja, 1987). In experiments with low levels of ethylene exposure during storage $(0.1,1.0$, and $\left.10 \mu \mathrm{L} \cdot \mathrm{L}^{-1}\right)$, the loss of quality was not detected until the sweetpotatoes were baked (Kitinoja, 1987). This result underscores the need to understand the implications of differential ethylene sensitivity and its role in sweetpotato cultivar storage performance.

In conclusion, our work provides evidence of the variable effect of 1-MCP on adventitious rooting in two sweetpotato cultivars. 'Beauregard' AR count and length varied in two of four experiments, but 'Evangeline' AR count was unaffected in all experiments. Blocking ethylene perception resulted in the delay of epidermal cell death that resulted in delayed emergence of AR primordia in 'Beauregard' sweetpotato cuttings. Ethylene appears to be involved in the death of nodal epidermal tissue at the site of AR emergence, similar to a mechanism previously described in rice. These results suggest that 'Beauregard' and 'Evangeline' cuttings differ in ethylene perception. Our data provide evidence of the role of endogenous ethylene in adventitious rooting of sweetpotato cuttings. Our results also represent the first evidence for genotype-specific ethylene involvement in adventitious rooting of sweetpotato cuttings.

\section{Literature Cited}

Blankenship, S.M. and J.M. Dole. 2003. 1Methylcyclopropene: A review. Postharvest Biol. Technol. 28:1-25.

Desmond, O.J., J.M. Manners, A.E. Stephens, D.J. Maclean, P.M. Schenk, D.M. Gardiner, A.L. Munn, and K. Kazan. 2008. The Fusarium mycotoxin deoxynivalenol elicits hydrogen peroxide production, programmed cell death and defence responses in wheat. Mol. Plant Pathol. 9:435-445.

Gamble, R.L., X. Qu, and G.E. Schaller. 2002. Mutational analysis of the ethylene receptor ETR1. Role of the histidine kinase domain in dominant ethylene insensitivity. Plant Physiol. 128:1428-1438.

Glick, B.R., B. Todorovic, J. Czamy, Z. Cheng, J. Duan, and B. McConkey. 2007. Promotioin of plant growth by bacterial ACC deaminase. Crit. Rev. Plant Sci. 26:227-242.

Hammet, H.L. 1983. Effects of holding sweet potato cuttings. Louisiana Agriculture Winter 1982-83:6-7.

Harbage, J.F. and D.P. Stimart. 1996. Ethylene does not promote adventitious root initiation in apple microcuttings. J. Amer. Soc. Hort. Sci. 121:880-885.

Kadner, R., U. Drüge, and F. Kühnemann. 2000. Ethylene emission of cuttings of pelargonium during the storage at different temperatures. Gartenbauwissenschaft. 6:272-279. [German with English abstract]

Kays, S.J. 1985. The physiology of yield in the sweet potato, p. 79-132. In: Bouwkamp, J. (ed.).
Sweetpotato products: A natural resource for the tropics. CRC Press, Boca Raton, FL.

Kays, S.J., J.D. Goeschl, C.E. Magnuson, and Y. Fares. 1987. Diurnal changes in fixation, transport, and allocation of carbon in sweetpotato using $11 \mathrm{C}$ tracer. J. Amer. Soc. Hort. Sci. 112: 545-554.

Kitinoja, L.A. 1987. Effects of low concentrations of ethylene on sweetpotatoes (Ipomoea batatas L. Lam) during curing and storage. Acta Hort. 201:37-42.

Li, S.W., L. Xue, S. Xu, H. Feng, and L. An. 2009. Mediators, genes and signaling in adventitious rooting. Bot. Rev. 75:230-247.

Macnish, A.J., R.T. Leonard, and T.A. Nell. 2011 Sensitivity of potted foliage plant genotypes to ethylene and 1-methylcyclopropene. HortScience 46:1127-1131.

Mao, L., F. Lu, and G. Wang. 2007. Application of 1-methylcyclopropene reduces wound responses and maintains quality in fresh-cut apple. Asia Pac. J. Clin. Nutr. 16:111-115.

Mergemann, H. and M. Sauter. 2000. Ethylene induces epidermal cell death at the site of adventitious root emergence in rice. Plant Physiol. 124:609-614.

Millenaar, F.F., M.C.H. Cox, Y.E.M. de Jong van Berkel, R.A.M. Welschen, R. Pierik, L.A. Voesenek, and A.J.M. Peeters. 2005. Ethyleneinduced differential growth of petioles in Arabidopsis. Analyzing natural variation, response kinetics, and regulation. Plant Physiol. 137: 998-1008.

Mortley, D.G., C.K. Bonsi, W.A. Hill, C.S. Williams, C.F. Davis, J.W. Williams, L.H. Levine, B.V. Petersen, and R.M. Wheeler. 2008. Influence of microgravity environment on root growth, soluble sugars, and starch concentration of sweetpotato stem cuttings. J. Amer. Soc. Hort. Sci. 133:327-332.

Mudge, K.W. and B.T. Swanson. 1978. Effect of ethephon, indole butyric acid, and treatment solution $\mathrm{pH}$ on rooting and on ethylene levels within mung bean cuttings. Plant Physiol. 61:271-273.

Pozo, L., R. Yuan, I. Kostenyuk, F. Alferez, G.Y. Zhong, and J.K. Burns. 2004. Differential effects of 1-methylcyclopropene on citrus leaf and mature fruit abscission. J. Amer. Soc. Hort. Sci. 129:473-478.

Rapaka, V.K., J.E. Faust, J.M. Dole, and E.S. Runkle. 2008. Endogenous carbohydrate status affects postharvest ethylene sensitivity in relation to leaf senescence and adventitious root formation in Pelargonium cuttings. Postharvest Biol. Technol. 272-282.

Serek, M., A. Prabucki, E.C. Sisler, and A.S. Andersen. 1998. Inhibitors of ethylene action affect final quality and rooting of cuttings before and after storage. HortScience 33:153-155.

St. Amand, P.C. and W.M. Randle. 1989. Ethylene production and wound healing in sweet potato roots. HortScience 24:805-807.

Steffens, B. and M. Sauter. 2005. Epidermal cell death in rice is regulated by ethylene, gibberellin, and abscisic acid. Plant Physiol. 139:713-721.

Togari, Y. 1950. A study of tuberous root formation in sweet potato. Bul. Nat. Agr. Expt. Sta. Tokyo 68:1-96 [Japanese with English summary].

Villordon, A., D.R. LaBonte, N. Firon, Y. Kfir, E. Pressman, and A. Schwartz. 2009. Characterization of adventitious root development in sweetpotato. HortScience 44:651-655.

Yu, Y.B., D.O. Adams, and S.F. Yang. 1980. Inhibition of ethylene production by 2,4-dinitophenol and high temperature. Plant Physiol. 66:286290. 